\title{
A numerical modeling of a profile velocity and Shear stress in transient flow applied in industrial technology
}

\author{
Hamdoun Sanaa ${ }^{1}$, Samri Hassan ${ }^{2}$, Bahrar Bennasser ${ }^{2}$ \\ ${ }^{1}$ Team of Fluid Mechanics and Environment, ENSETM, SSDIA Laboratory, FST Mohammedia, Hassan II University Casablanca, \\ Morocco \\ ${ }^{2}$ Team of Fluid Mechanics and Environment, ENSETM, Condensed Matter Physics Laboratory, FST Mohammedia, Hassan II \\ University Casablanca, Morocco
}

\section{Article Info}

Received Jul 12, 2018

Keyword:
Velocity profiles
shear stress
laminar flow
Polynomial expansion
Characteristics method

\begin{abstract}
This research is devoted to theoretical and numerical models of transient shear stress in a transient laminar flow over the pipe wall. This work is an elementary method of the model Prado et al, which the base is on the expansion of velocity profiles ofthe flow in polynomial series of a radial space at acroass the right section of pipe. The set equations is derived from mass and momentum conservation laws. The system partial derivatives equations obtained is hyperbolique and suitable by the method of characteristics. This model is approved with the experimental results of Holmboe et al, and, Vardy et al. This digital code can be possible to join it in any tools, to simulateand to controle water hammer in pipe.
\end{abstract}

\section{Corresponding Author:}

\author{
Hamdoun Sanaa \\ Team of Fluid Mechanics and Environment, ENSETM, \\ SSDIA Laboratory, FST Mohammedia, \\ Hassan II University Casablanca, \\ BP.159 Mohammedia Principale, Morocco \\ Email: sanaa.hamdoun @gmail.com
}

\section{Introduction}

Nowadays, in transient flow in pipe, the important part of the energy dissipation is caused by the pressure loss produced by the friction of the fluid on the wall of the pipe. The friction term in transient flow in pipe is opposed to the friction ofquasi-steady state flow, Streeter and Wylie [3, 4]. This discordances is presented by a difference in velocity profile, turbulence and transition from laminar to turbulent flow and vice versa. There are different unsteady friction models, which have beendiscussed in the literature. We cite, principally, the works of Zielke [5], Trikha [6], Kagawa et al. [7], Brown [8], Suzuki et al. [9], and Vardy et al. [10]. In these researchs, the friction term depend on instantaneous mean flow velocity $\mathrm{V}$ and the instantaneous velocity profiles.

Brunone et al. [11], has expreshed the friction term in dependance with instantaneous mean flow velocity V, local acceleration and instantaneous convective acceleration. In general, difficulties arise in analysis of transient turbulent flow. Models from the literature are found for many flow conditions where as the development of a general friction model in transient turbulent flow is a subject of intensive research worldwide.

In comparison to these one-dimensional models, Vardy et al. [11] developed a two-dimensional model. This work shows that, contrary to the quasi-stationary regime, the velocity profiles are not parabolic. Recently, to have an estimation of the wall shear stress in a transient laminar flow in pipes, Prado et al. [1] have developed 
a semi-analytical method based, essentially, on the polynomial series expansion of instantaneous axial velocity profiles as function of radial variable and time in a section of pipe. This method is associeted to the method of characteristics.

This study is, essentially, concerned to a relatively simple adaptation of this model to compute, numerically, the velocity profiles, pressure, mean flow velocity and wall shear stress in the transient flow in elastique a linear elastic pipe. The set differential equations obtained are of hyperbolic type and suitable to be resolved by the method of characteristics.

\section{Assumptions and Basic equations}

This research is based on the assumption of ax symmetric unsteady flow of Newtonian, isentropic and compressible fluid. The deformation of the pipe wall is elastic linear. The inertia expressions are insignificant and the pipe is modeled by a juxtaposition of independent rings without mass. The radius of the pipe is sufficiently insignificant compared with its length enough that the current lines of fluid are straightlines Assume, furthermore, that the longitudinal velocity gradients are very low correlated with the transverse gradients.

We have to find the solution of the following set of derivative partial equations:

$$
\begin{gathered}
\frac{\partial p}{\partial t}+\rho a^{2}+\frac{\partial V}{\partial x}=\mathbf{0}(1) \\
\frac{1}{\rho} \frac{\partial p}{\partial x}+\frac{\partial V}{\partial t}=S_{0}(2) \\
\frac{\partial V_{i}}{\partial t}+\frac{1}{\rho} \frac{\partial P}{\partial x}=S_{i}(3)
\end{gathered}
$$

\section{Modeling the wall stress}

The numerical solution of hyperbolic systems (1), (2) and (3) associated with initial and boundary conditions can easily be acquired by the ordinary method of characteristics [16], [17]. The system can be integrated by the method of finite differences over the characteristic curves slope \pm aet 0 . This leads to the following algebraic relationship, to have the values of the various parameters at time $n+1$ as a function of those at time n:

$$
\mathrm{V}_{\mathrm{l}}^{\mathrm{n}+1}-\mathrm{V}_{\mathrm{l}-1}^{\mathrm{n}}+\frac{1}{\rho \mathrm{a}}\left(\mathrm{P}_{\mathrm{l}}^{\mathrm{n}+1}-\mathrm{P}_{\mathrm{l}-1}^{\mathrm{n}}\right)=\left.\mathrm{S}_{0}\right|_{\mathrm{l}-1} ^{\mathrm{n}} \Delta \mathrm{t}
$$

Along the characteristic of slope $\mathrm{dx} / \mathrm{dt}=+\mathrm{a}$

$$
\mathrm{V}_{\mathrm{l}}^{\mathrm{n}+1}-\mathrm{V}_{\mathrm{l}+1}^{\mathrm{n}}+\frac{1}{\rho \mathrm{a}}\left(\mathrm{P}_{\mathrm{l}}^{\mathrm{n}+1}-\mathrm{P}_{\mathrm{l}+1}^{\mathrm{n}}\right)=\left.\mathrm{S}_{0}\right|_{\mathrm{l}+1} ^{\mathrm{n}} \Delta \mathrm{t}
$$

Along the characteristic of slope $\mathrm{dx} / \mathrm{dt}=-\mathrm{a}$

$$
\left.\mathrm{V}_{\mathrm{i}}\right|_{\mathrm{l}} ^{\mathrm{n}+1}-\left.\mathrm{V}_{\mathrm{i}}\right|_{\mathrm{l}} ^{\mathrm{n}}-\left(\left.\mathrm{V}_{0}\right|_{\mathrm{l}} ^{\mathrm{n}+1}-\left.\mathrm{V}_{\mathrm{i}}\right|_{\mathrm{l}} ^{\mathrm{n}}\right)=\left(\left.\mathrm{S}_{\mathrm{i} 0}\right|_{\mathrm{l}} ^{\mathrm{n}}-\left.\mathrm{S}_{0}\right|_{\mathrm{l}} ^{\mathrm{n}}\right) \Delta \mathrm{t}
$$

\section{Initial and Boundary conditions}

The initial conditions are completely created a steady and laminar flow of Reynolds number less than 2100, and the balance for the pipe wall. At time $t=0$, the valve is unexpectedly closed. The boundary conditions are added to the pressure forced by the tank on the upstream end, the instantaneous closing of valve on the downstream. 


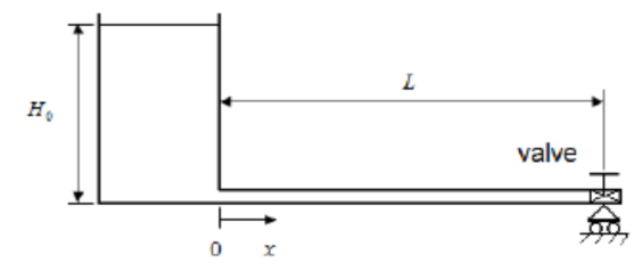

Figure 1. Diagram of the system studied

\section{Flowchart of the overall system resolution process}

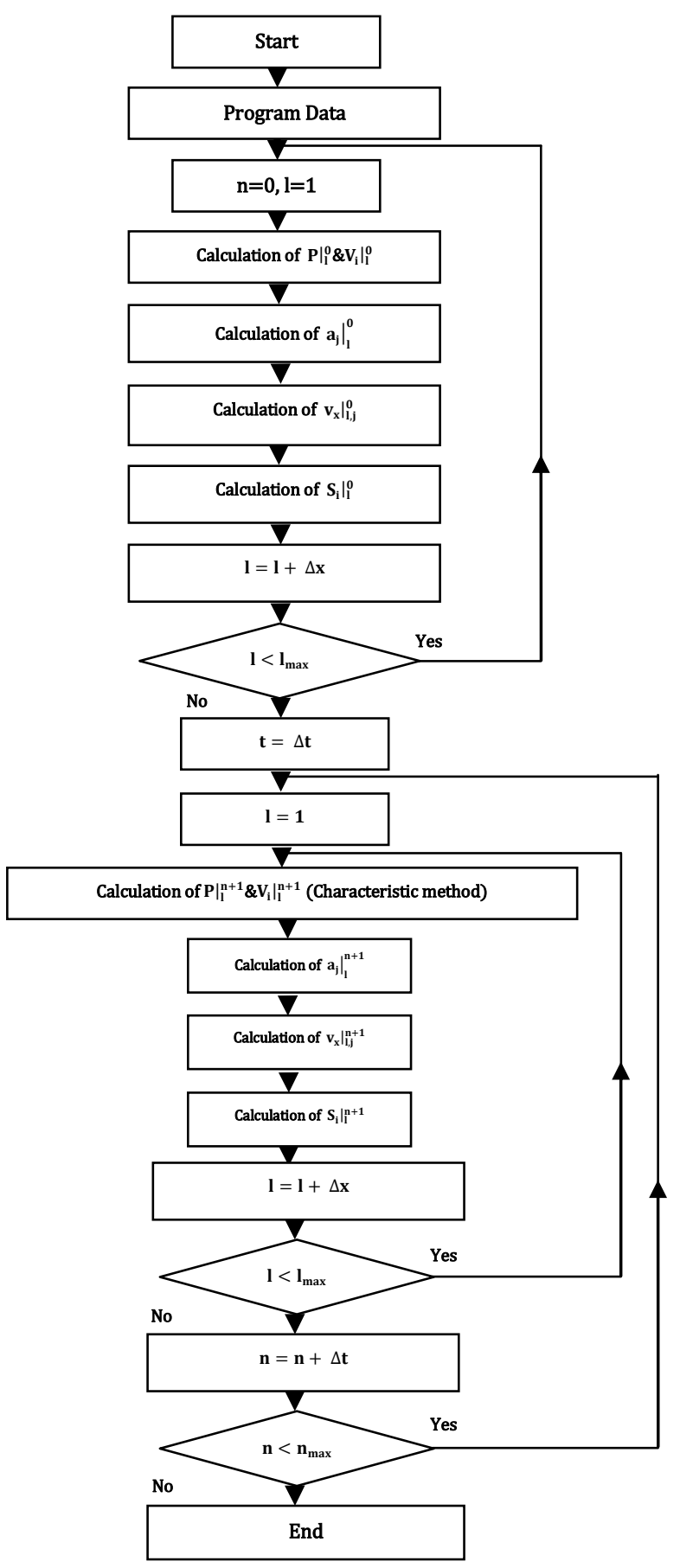




\section{Applications And Results}

We estimate the response in pressure and velocity at the instantaneous valve closing .First we proceed to the validation of the code calculation by comparing the results of this model with those given by the experience of Holmboe et al. Roll [53], Zielke [12] and Vardy et al. [46].

The calculation data is shown in the summary table below:

Table 1: Installation Characteristics

\begin{tabular}{|c|c|c|c|c|c|c|}
\hline Pipe radius $\mathrm{R}$ & $\begin{array}{c}\text { Pipe } \\
\text { length } \mathrm{L}\end{array}$ & $\begin{array}{l}\text { Density of } \\
\text { the fluid } \rho\end{array}$ & $\begin{array}{l}\text { Kinematic } \\
\text { viscosity v }\end{array}$ & $\begin{array}{c}\text { Water } \\
\text { hammer } \\
\text { celerity a }\end{array}$ & $\begin{array}{l}\text { The steady state } \\
\text { velocity before } \\
\text { closing the valve } \\
\text { V0 }\end{array}$ & $\begin{array}{c}\text { Reynolds } \\
\text { number Re }\end{array}$ \\
\hline
\end{tabular}

$\begin{array}{ccccc}0.0127 \mathrm{~m} & 800 & 39.6710- & 1324.4 \mathrm{~m} / \mathrm{s} & 0.128 \mathrm{~m} / \mathrm{s} \\ & \mathrm{Kg} / \mathrm{m} 3 & 6 \mathrm{~m}^{2} / \mathrm{s}(\text { at } \\ & \left.27^{\circ} \mathrm{C}\right),\end{array}$

$81.95[--]$

We analyze, in the following, the influence of the parameters of combinations associated with developments in polynomial series, of the velocity profile of the flow. We choose, for each example, the models associated with the following sets:

* Model with 5 parameters: $J_{a}=\{2,6,8,10,12\}$
* Model with 7 parameters: $J_{b=\{2,4,6,8,10,11,12\}}$.

In these applications, we examinate the response to fast closing of the valve at the downstream of the pipe. The figures $2,3,4,5$ and 6 are the evolution versus time, of the non-dimensional presentations of the pressure and the mean velocity of the flow at the pipe midpoint and at the valve downstream of the pipe. The graph of the figure 2depiced for the present model, in quasi steay model, and with taking into account the effect of velocity profils. This graph highlights that these results are in agreement with those measured by Hombloe et al.

The graphs in the figure 3,4 5and 6 show, in the same conditions, the evolution versus time ofnon-dimensional average pressure, average velocity and stress at the median of the pipe. The results for each figure show the superposition of different options against the quasi-stationary state. So we can notice the clear difference between the quasi-stationary model and the model presented. However, we can deduct from the graphs that the intermediate velocity and pressure do not depend upon the order of the polynomial approximation of profiles velocity. These results are, qualitatively, correlated to those found by Holmboe et al. and are agree perfectly.

The figure 7 shows that this model, allows, in addition to the pressure, intermediate velocity and stress to have further information on the velocity profiles in transient laminar flow in pipe. 

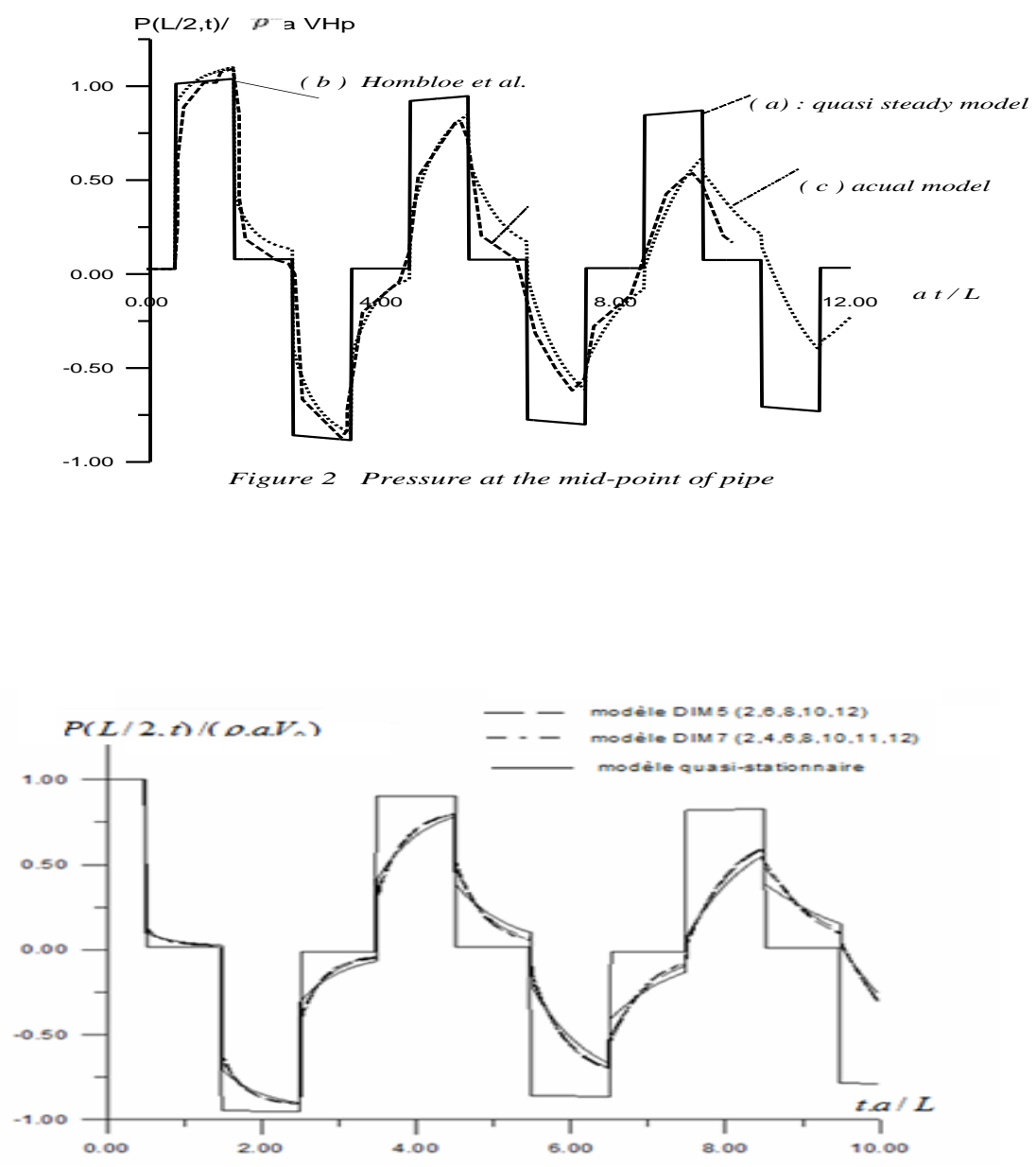

Figure 3. Pressure at the valve

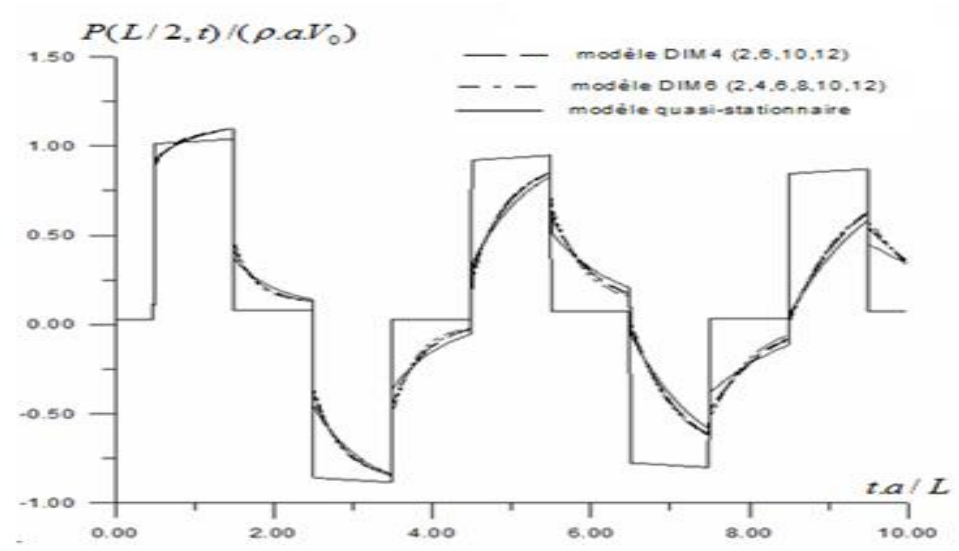

Figure 4. Pressure at the mid-point of pipe 


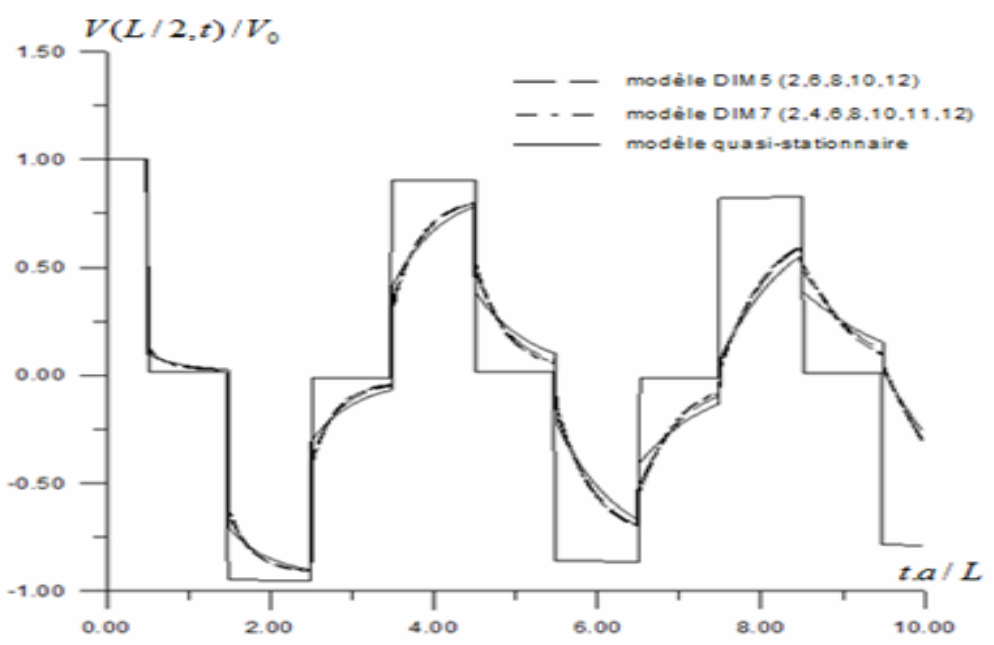

Figure 5. Mean velocity at the pipe midpoint

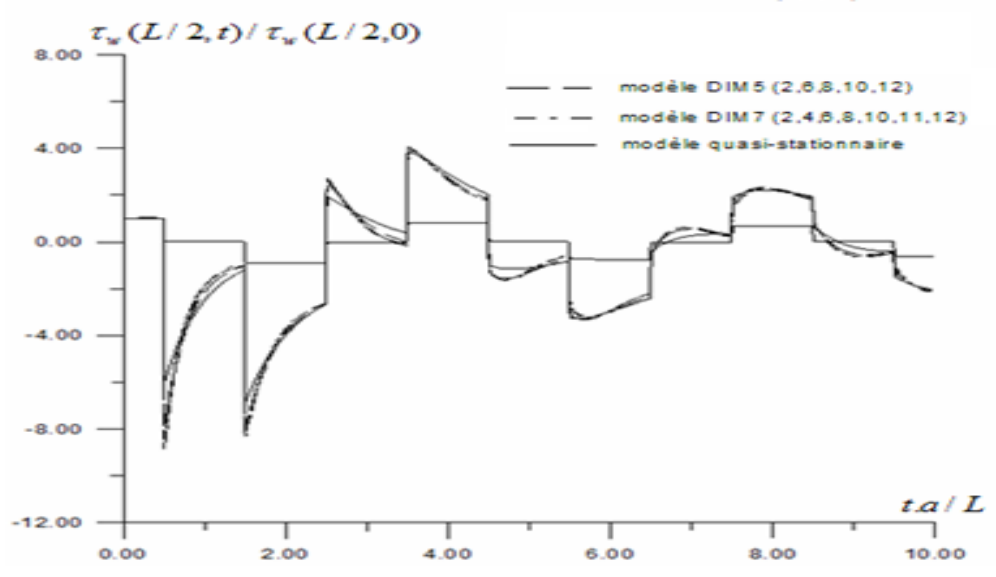

Figure 6. Stress at the pipe midpoint

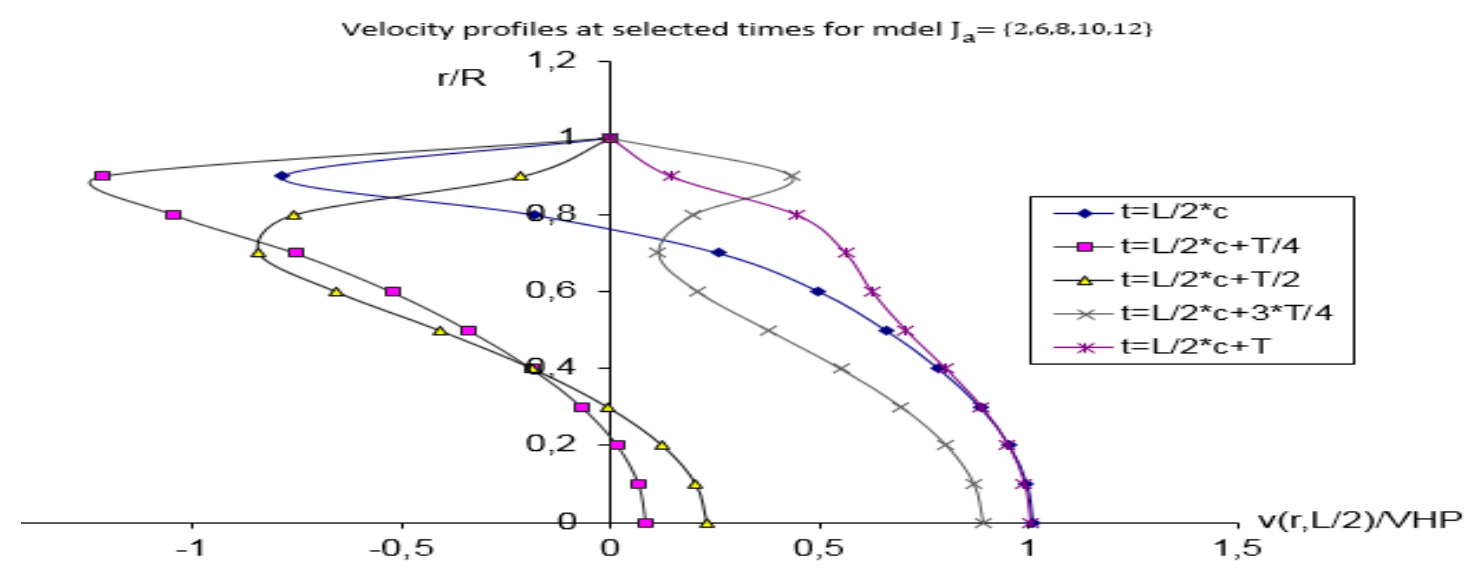

Figure 7. Velocity profiles at selected times 


\section{Conclusion}

We can conclude from this study that, compared to the quasi-stationary flow model, this model takes into the account the variation of velocity profiles has many advantages to introduce an important correction to the transient stress of flow in pipe. However, we obtain that the augmentation of the degree polynomial expansion of velocity profiles has many effects on the velocity profiles but not on the mean velocity, pressure and stress of flow on pipe. All results for average pressure, average velocity and shear stress of the chosen sets are close to each other.

This model has the benefit to require little additional terms to have a better representation of the wall shear stress and, thus, it can be easilyused a long side the existing codes to measure the laminar transient flow in pipes.

\section{References}

[1] E. L. Holmboe, W. T. Rouleau, The effect of viscous shear on transient in liquide lines, Journal of Basic Engineering ASME, 89 (1967), 140 - 148.

[2] V. L. Streeter, E. B. Wylie, Fluid Transients, McGraw-Hill, New York, USA, 1978.

[3] E. B. Wylie, Advances in the use of MOC in the unsteady flow, Proc. 4th Int. Con/. On Pressure Surges, BHRA, Bath, England, (1983), 27 - 36.

[4] W. Zielke, Frequency-dependent friction in transient pipe flow, Journal of Basic Engineering, ASME, 90 (1968), $109-115$.

[5] E. B. Wylie, Advances in the use of MOC in the unsteady flow, Proc. 4th Int. Con/. On Pressure Surges, BHRA, Bath, England, (1983), 27 - 36.

[6] F. T. Brown, On weighting functions for the simulation of unsteady turbulent Flow, Forun on Unsteady Flow, ASME, New Orleans, USA, FED, 15 (1984), 26 - 28.

[7] S. Jing-Chao, C. Yigang, An efficient approximate expression for transient flow of high viscous fluid in hydraulic pipelines, Proc. 6th Int. Con/. On Pressure Surges, BHRA, Cranfield, England, (1989), 349 356.

[8] K. L. Hwang, A. E. Vardy, A characteristics model of transient friction in pipes, Journal of Hydraulic Research, IAHR, 29 (1991), 669-684.

[9] B. Brunone, U. M. Golia, and M. Greco, Some remarks on the momentum equation for fast transients, Int. Meeting on Hydraulic Transients with Column Separation. 9th Round Table, IAHR, Valencia, Spain, (1991), $140-148$.

[10] VARDY, A.E., HWANG, K.L., and BROWN, J.M.B (1993). A weighting function model of transient turbulent pipe flow. Journal of hydraulic research, IAHR 31(4), 533-548.

[11] Prado R.A. \&Larreteguy Axel E. (2002) A transient shear stress model for the analysis of laminar waterhammer problems, Journal of Hydraulic Research, Vol. 40, No.1, pp. 45-53.

[12] Gökhan Ömeroğlu. A scrutiny study on wave energy potential and policy in TURKEY. Periodicals of Engineering and Natural Sciences. Vol. 7, No. 1, June 2019, pp.458-464.

[13] Dileep bp, Vitala H R.Mechanical and Tribological Characterization Nitrided Al-7075/Al2O3 Metal Matrix Composites. Periodicals of Engineering and Natural Scinces. Vol.6, No.2, October 2018, pp. 64 70. 
[14] Andrey Dunin, Mikhail Shatrov, Valerii Malchuk, Sergei Skorodelov, Vladimir Sinyavski, Andrey Yakovenko. Simulation of fuel injection through a nozzle having different position of the spray holes. Periodicals of Engineering and Natural Scinces. Vol. 7, No. 1, June 2019, pp.458-46 